\title{
Prediction of austenite grain growth during austenitization of a $0.7 \%$ C pearlitic rail steel
}

\author{
S Khanyema ${ }^{1, a}$, KA Annan ${ }^{1, b}$, RJ Mostert ${ }^{1, c}$, CW Siyasiya, ${ }^{1, d}$ J Moema ${ }^{2, e}$ \\ ' University of Pretoria, Department of Materials Science and Metallurgical Engineering, Private bag X20, Hatfield 0002, Pretoria, \\ South Africa \\ ${ }^{2}$ Advanced Materials Division (AMD), Mintek, 200 Malibongwe Drive, Randburg, 2125, South Africa

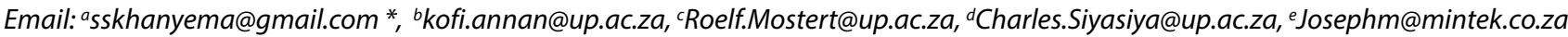

\begin{abstract}
The prior austenite grain size of steels greatly influences the phase transformation kinetics during austenitization and the microstructure which determines the mechanical properties. The effect of temperature and time on austenite grain growth of $0.7 \%$ carbon rail steel during reheating was studied. The grain growth behaviour of this steel was investigated under different heating temperatures and holding times at a constant heating rate of $4^{\circ} \mathrm{C} / \mathrm{min}$. Samples were heated in a tube furnace at temperatures of 1150,1200 and $1250^{\circ} \mathrm{C}$ and held for $0,1800,3600,5400,7200$ and 9000 seconds before quenching into water. The prior austenite grains were observed using an optical microscope and austenite grain sizes were measured by the linear intercept method. The measured austenite grain sizes were used in determining the grain growth constants $\mathrm{Q}$, $\mathrm{A}$ and $\mathrm{n}$ which were used in developing the constitutive equation for grain growth prediction. A good agreement was found between the actual and the predicted austenite grain size within the typical industrial soaking temperature range of 1150 and $1200^{\circ} \mathrm{C}$.
\end{abstract}

The constitutive equation was found to be $\mathrm{D}^{4.5}=\left[6 \times 10^{19} \exp \left(-\frac{355 \times 10^{3}}{R T}\right) t\right]$

Keywords: Microstructure, grain growth, austenite, pearlite, temperature, time

\section{Introduction}

Pearlitic steels are widely used for railway rails due to their high yield strength, good fatigue strength, good wear resistance and excellent weldability (Beynon and Perez-unzueta 1993).

During the manufacturing process, the steels are austenitized and soaked for a specific period. The soaking temperature and time are the primary controlling variables in the austenitization process, as the starting grain structure influences the final grain structure and the properties entailed by the steel (Duan, et al., 2010). These two parameters also affect the grain growth behaviour through the dissolution and distribution of precipitates. The austenitizing temperature and time, control the prior austenite grain size, austenite recrystallization, refinement and phase transformation in the steel during reheating and on cooling (Sha and Sun, 2009). The pearlite structure, which provides strength to this type of steel results from eutectoid decomposition of austenite through growth of ferrite and cementite lamellae. The production process of pearlitic steels therefore entails careful consideration of the chemical composition and process conditions that will lead to the formation of pearlite structure. It is worthy to note that the mechanical properties of steels greatly depend on the fraction of phases produced following the thermomechanical processing conditions. High yield strength, wear resistance and high hardness are some of the properties required for rail application steels and they are achieved through careful control of the grain structure and size during processing. Very high austenitizing temperatures and long holding times may result in grain growth, distortion and loss of metal strength
(Porter, et al., 1992). It has been pointed out that temperature and time greatly influence austenite grain growth and eventually the mechanical properties of the steels, with temperature being the most effective parameter (Annan, et al., 2015; Lee and Lee 2008; Zhang et al. 2011). Due to the difficulty and limitations posed by in-situ measurement of grain size during heat treatments, to monitor grain growth behaviour, it has become ideal to study the grain growth behaviour of steels through the use of constitutive prediction equations. The kinetics of grain growth in metals have been widely studied, especially for low carbon micro alloyed steels, looking at the effects of various alloying elements, and many models specific to those steels that have been developed (Annan, et al, 2018; Zhang et al. 2011). The control of austenite grain growth in medium to high carbon steels have focused largely on the impact of chemical composition on grain structure control. The objective of the current work is to study the effects of austenitizing temperature and time on the grain growth of $0.7 \% \mathrm{C}$ rail steel through the development of a constitutive equation to predict the grain behaviour during austenitization.

\section{Material and experimental procedure}

The material used in the current study is $\mathrm{C}-\mathrm{Mn}$, grade $\mathrm{R} 260$ rail steel. The chemical composition of the studied steel is shown in Table 1.

In order to obtain the effect of austenitizing temperature and holding time on the austenite grain growth, square samples of $10 \mathrm{~mm} \times 10 \mathrm{~mm} \times 5 \mathrm{~mm}$ were heated in a vertical tube furnace 
Table 1: Chemical composition of the R260 rail steel used in the study, in mass \%

\begin{tabular}{ccccccccccc}
\hline $\mathbf{C}$ & $\mathbf{M n}$ & $\mathbf{S i}$ & $\mathbf{P}$ & $\mathbf{S}$ & $\mathbf{C r}$ & $\mathbf{A l}$ & $\mathbf{V}$ & $\mathbf{N i}$ & $\mathbf{N}$ \\
\hline 0.73 & 1.17 & 0.32 & 0.015 & 0.01 & 0.04 & 0.001 & 0.025 & 0.01 & 0.008 \\
\hline
\end{tabular}

at temperatures of 1150,1200 and $1250^{\circ} \mathrm{C}$ using a heating rate of $4^{\circ} \mathrm{C} / \mathrm{min}$ and held for times of $0,1800,3600,5400,7200$ and 9000 seconds before being subsequently quenched into water at room temperature. Figure 1 shows the schematic thermal profile of the heat treatment used. The austenitizing temperatures and times used in this investigation are comparable to typical conditions used in the rail manufacturing plants. Quenched specimens were metallographically prepared and etched with Picral to reveal prior austenite grain structures. The austenite grain structures were observed using an Olympus optical microscope and grain sizes were measured using linear intercept method with the help of Image $J$ software. Average grain size measurements were done on 3 to 4 representative areas from each sample at 100x magnification as recommended in ASTM E112.

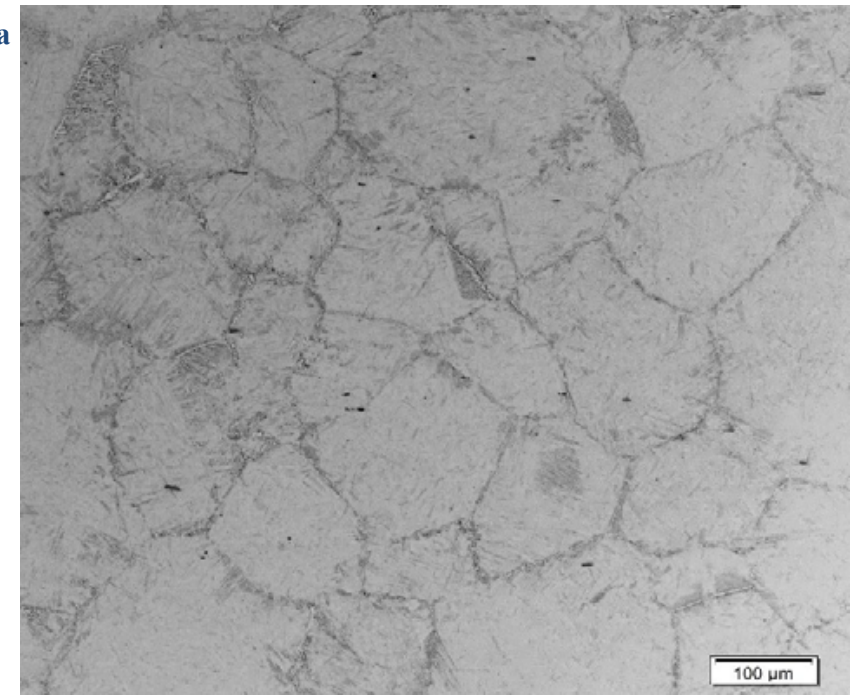

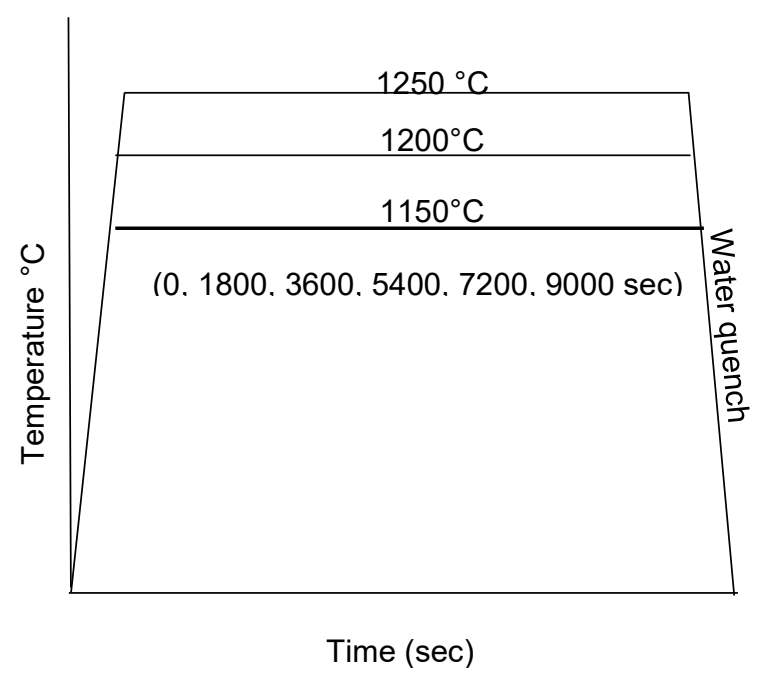

Figure 1: Schematic diagram of the heat treatment profile used in the study
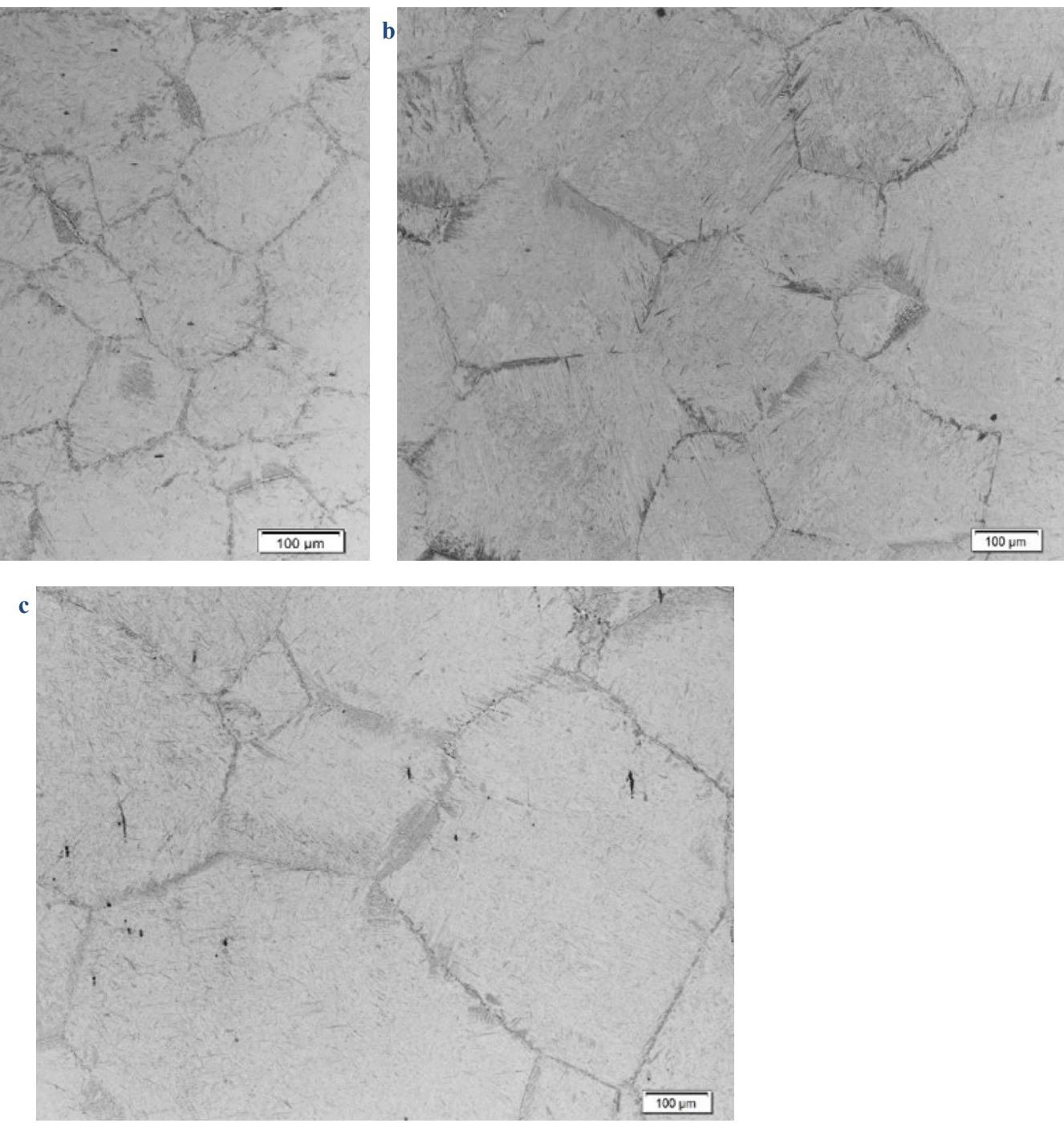

Figure 2: Optical micrographs of steel heat treated for 3600s and austenitizing temperatures of (a) $1150^{\circ} \mathrm{C}$ (b) $1200^{\circ} \mathrm{C}$ (c) $1250{ }^{\circ} \mathrm{C}$. All images taken at $100 \mathrm{x}$ magnification 

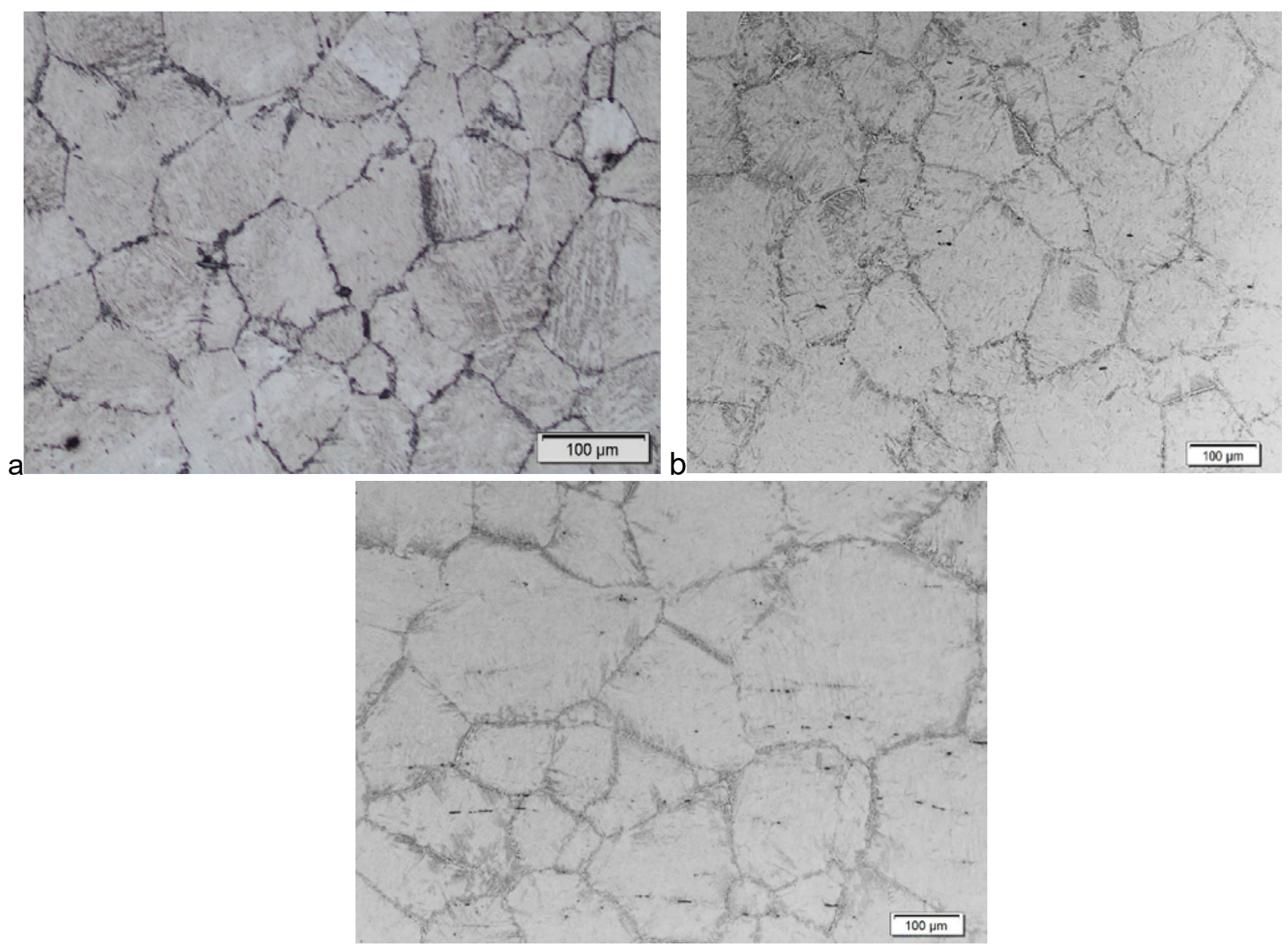

Figure 3: Optical micrographs of steel heat treated at 1150 for a). $1800 \mathrm{~s}$ b). $3600 \mathrm{~s}$ and c). 7200 s all images taken at 100x magnification

\section{Results and Discussion}

\subsection{Microstructural analysis}

Figure 2 shows the optical micrographs of the steel samples heat treated at the different austenitizing temperatures and held at the same soaking time. It is visually, observed from these images that there is an increase of grain size as the austenitizing temperature increased. At temperatures 1200 and $1250^{\circ} \mathrm{C}$ in Figures 2(a) and (b) abnormal grain growth is observed, in a form of unequal grain sizes distribution (Hodgson and Gibbs, 1992).

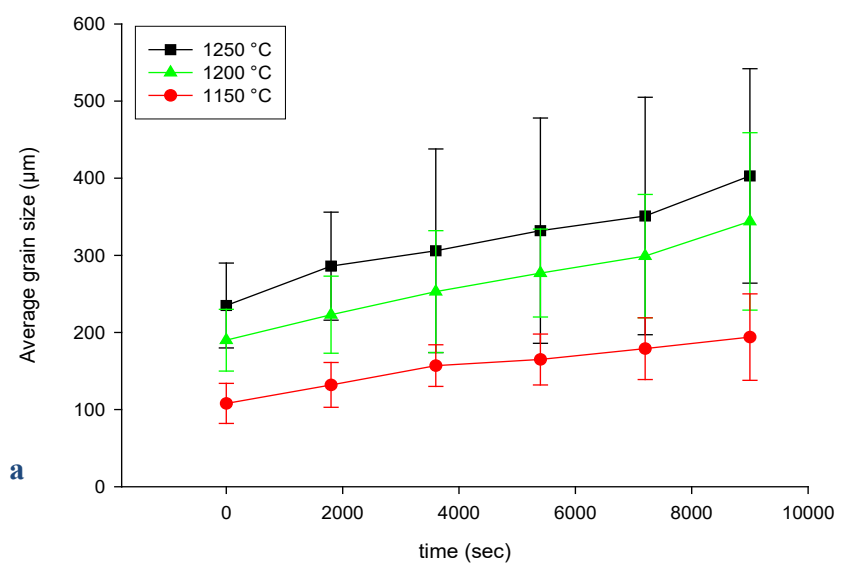

Figure 3, presents the micrographs of steel samples heat treated at the same austenitizing temperature but held for different soaking times. There is an observation of increased grain size with increased holding times. The observed increased grain size with increase in temperature and time is comparable to results reported by many authors (Annan, et al, 2018, Hodgson and Gibbs, 1992, Zhang, et al, 2011). It is understood that at $1200^{\circ} \mathrm{C}$ and above, the carbides which are effective in pinning grain boundaries, to control the grain growth, have all dissolved and therefore leading to a rapid increase in grain growth.

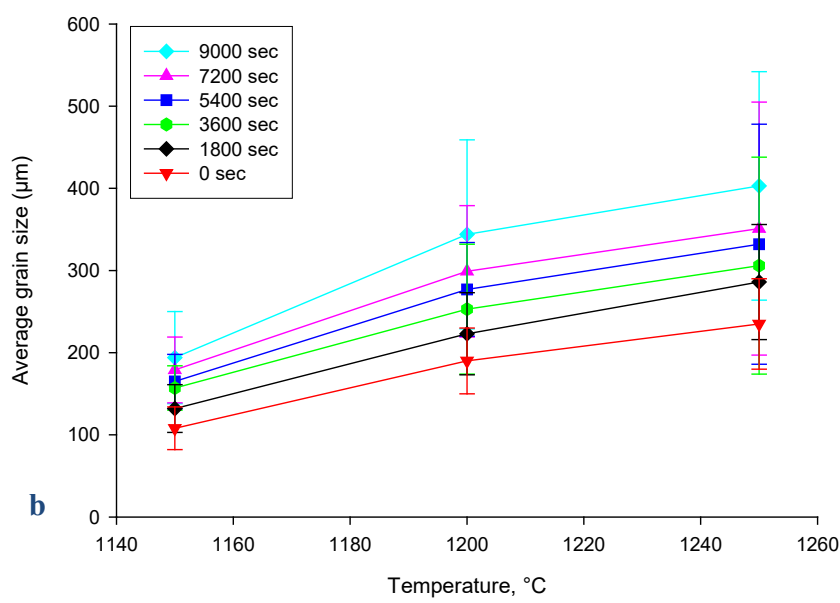

Figure 4: Isothermal grain growth behaviour of austenite in steels showing an increase in grain size with a) time and b) temperature 


\subsection{Effect of time and temperature on austenite grain size}

Quantitative analysis of the experimentally measured austenite grain sizes as a function of temperature and time is shown in Figure 4. The graphs evidently display the influence of time and temperature on grain growth in the steel with temperature proven to be more effective than time.

\subsection{The development of a constitutive equation using the constants $n, Q$ and $A$}

The Arrhenius type constitutive equation developed by Whiteman and Sellars, 1979 used to study austenite grain growth under isothermal conditions, shown in Equation 1, was used in the current study.

$$
D^{n}-D_{o}^{n}=A t \exp \left(-\frac{Q}{R T}\right)
$$

Where $D$ is the mean grain size, $D_{o}$ is the initial grain size, $n$ is the grain growth exponent, $A$ is a material constant, $t$ is time, $Q$ is the activation energy for grain growth, $R$ is the gas constant $(8.314 \mathrm{~J} /$ $\mathrm{mol} / \mathrm{k}$ ), and $T$ is temperature in Kelvin.

Considering that $D>>D_{\mathrm{o}}$ and that $D_{\mathrm{o}} \approx 0$, Equation 1 can be rewritten as Equation 2:

$$
\mathrm{D}=\left[\operatorname{Atexp}\left(-\frac{Q}{R T}\right) t\right]^{1 / n}
$$

By taking natural logs (ln) on both sides of Equation 2, Equation 3 is obtained. When a plot of $\ln \mathrm{D}$ versus $\ln t$ is constructed, the slope of the graph is $1 / n$ (see Figure 5) and the value of the grain growth exponent $n$ can thus be determined as follows:

\section{$\frac{1}{n}=\frac{\partial \ln D}{\partial \ln t}$ with $\mathrm{T}$ kept constant}

Eqn. 3

From the grain growth empirical Equation 4

$$
D^{n}=K t
$$

Eqn. 4

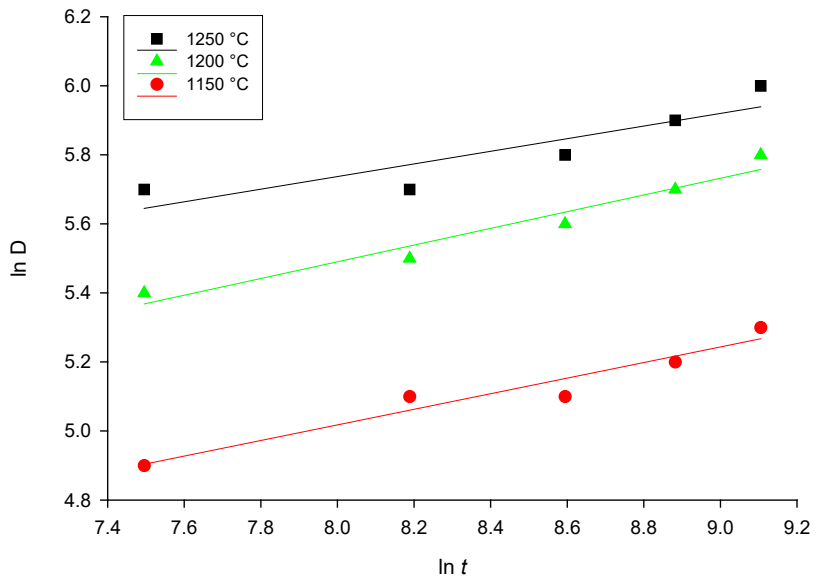

Figure 5: The plot of $\ln \mathrm{D}$ as a function of $\ln t$
Making $K$ the subject of Equation. 4, implies;

$$
K=\frac{D^{n}}{t}
$$

From Equation 5, the value of $K$ was calculated for different temperatures and times using the measured $D$ values and the $n$ determined from Figure 5 .

From Equation 1, $K$ is a temperature dependant constant given by;

$$
K=K_{o} \exp \left(\frac{-Q}{R T}\right)
$$

Taking natural $\operatorname{logs}$ to base $10(\ln )$ on both sides of Equation 6 , using two variables $\mathrm{K}_{1}$ and $\mathrm{K}_{2}$, Equations 7 and 8 were constructed.

$$
\begin{aligned}
& \ln K_{1}=\frac{-Q}{R T_{1}}+\ln A_{1} \\
& \ln K_{2}=\frac{-Q}{R T_{2}}+\ln A_{2}
\end{aligned}
$$

Since $\mathrm{A}$ is a material constant, $\mathrm{A}_{1}=\mathrm{A}_{2}=\mathrm{A}$, therefore subtracting Equation 7 from Equation 8;

$$
\ln \left(\frac{K_{2}}{K_{1}}\right)=\frac{Q}{R}\left(\frac{Q}{R T_{1}}-\frac{Q}{R T_{2}}\right)
$$

Hence, with $K_{1}$ and $K_{2}$ determined at temperature $T_{1}$ and $T_{2}$, Q was calculated using Equation 10;

$Q=\frac{\ln \left(\frac{K_{2}}{K_{1}}\right) R}{\left(\frac{1}{T_{1}}-\frac{1}{T_{2}}\right)}$

Then from, Equation 1 when $D_{0}=0$ );

$$
D^{n}=A \exp \left(\frac{-Q}{R T}\right) t
$$

hence, A was determined using Equation 11 as:

$$
A=\frac{D^{n}}{\exp \left(\frac{-Q}{R T}\right) t}
$$

The constants $\mathrm{n}, \mathrm{A}$ and $\mathrm{Q}$ generated from the current study in comparison with existing values in the literature are presented in Table 2.

Table 2: Comparable austenite grain growth constants

\begin{tabular}{llll}
\hline Author & n & Q (kJ/mol) & A \\
\hline Yue, et al., 2009 & 0.36 & 458 & $3.12 \times 10^{19}$ \\
Chamanfar, et al., 2020 & 0.20 & 230 & $4.2 \times 10^{16}$ \\
Current study & 0.22 & 355 & $6 \times 10^{19}$ \\
\hline
\end{tabular}

The generated constants were used in developing the constitutive Equation 12.

$\mathrm{D}^{4.5}=\left[6 \times 10^{19} \exp \left(-\frac{355 \times 10^{3}}{R T}\right) t\right]$

Figure 7, shows the plot of predicted austenite grain size against measured grain size over the tested temperature ranges using the 


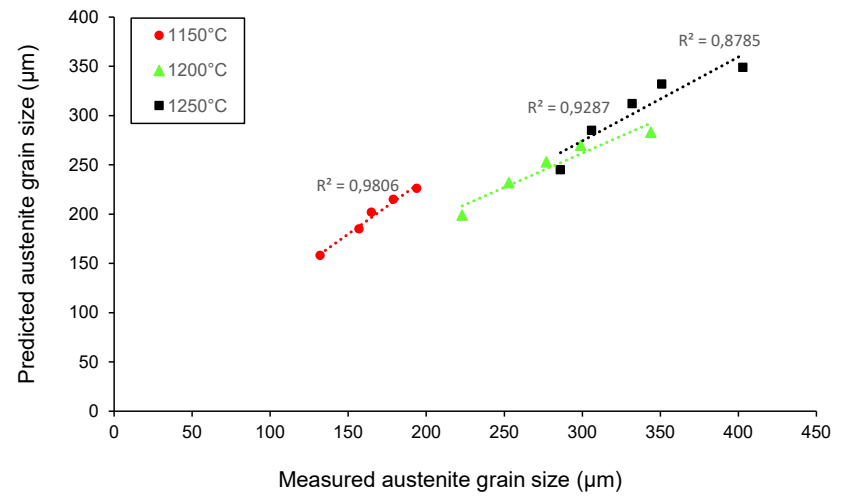

Figure 7: Comparison of predicted and experimental grain growth behaviour in the steels

constitutive equation developed in the current work. The figure indicates a very good prediction capability of the developed constitutive equation for $1150^{\circ} \mathrm{C}$ and $1200^{\circ} \mathrm{C}$, with co-efficient of determination of 0.98 and 0.93 respectively.

\section{Conclusion}

In the present study, the effect of temperature and time on austenite grain growth behaviour was studied. Based on results and analysis done, the conclusions below are drawn:

1. Grain growth in the $0.7 \% \mathrm{C}$ steel studied, was found to increase with increasing temperature and time. Temperature was however found to be more effective in increasing grain size than time.

2. The grain growth constants $\mathrm{n}, \mathrm{Q}$ and $\mathrm{A}$ were found to be 0.22 , $355 \mathrm{KJ} / \mathrm{mol}$ and $6 \times 10^{19}$ respectively.

3. The constitutive equation developed for predicting grain size of this studied steel with a temperature range of $1150^{\circ} \mathrm{C}-1200^{\circ} \mathrm{C}$ is $D^{4.5}=\left[6 \times 10^{19} \exp \left(-\frac{355 \times 10^{3}}{R T}\right) t\right]$

4. The prediction capability of the current developed constitutive equation is found to be very good as compared with the measured values of grain sizes.

\section{Acknowledgements}

The authors would like to thank MINTEK for financial support, Arcelor Mittal SA and Highveld structural for the provision of samples and the University of Pretoria for the provision of equipment and academic support.

\section{Author Contribution}

Experimentation, formal analysis, writing up: S. Khanyema Writing up, analysis and review: Kofi A. Annan
Conceptualization, funding acquisition, analysis and review:

\section{R Mostert}

Project administration, review - C.W. Siyasiya

Funding acquisition, review: Joseph Moema

\section{References}

1. Annan, K. A., C. W. Siyasiya, and W. E. Stumpf. 2015. "The Influence of Niobium Content on Austenite Grain Growth in Microalloyed Steels." Journal of the Southern African Institute of Mining and Metallurgy 115 (10): 973-80.

2. Annan, K.A, Siyasiya, C.W. and Stumpf, W.E. 2018. Austenite Grain Growth Kinetics after Isothermal Deformation in Microalloyed Steels with Varying Nb Concentrations. ISIJ, Vol.58 Issue 2, pp 333-339.

3. Beynon, J. and Perez-unzueta, A. 1993. "Microstructure and Wear Resistance of Pearlitic Rail Steels." Wear 162-164: 173-82.

4. Burke, J. E., and Turnbull, D. 1952. "Recrystallization and Grain Growth." Progress in Metal Physics 3 (C). https://doi. org/10.1016/0502-8205(52)90009-9.

5. Duan, Lin na, Ji man Wang, Qing you Liu, Xin jun Sun, and Jian chun Cao. 2010. "Austenite Grain Growth Behavior of X80 Pipeline Steel in Heating Process." Journal of Iron and Steel Research International 17 (3): 62-66.

6. Farrell, K, and P R Munroe. 1996. "Grain growth in Fe-30at .\% Al." Scripta Materialia. Vol 35 (5): pp 615-21.

7. Gao, Q., Fu Q., Hailian Z. and Qiang H. 2016. "Austenite Grain Growth in Alumina-Forming Austenitic Steel." Journal of Materials Research 31 (12): 1732-40. https://doi.org/10.1557/jmr.2016.178.

8. Hodgson, P and Gibbs, R.1992. A mathematical model to predict the mechanica; properties of hot rolled C-Mn and microalloyed steel. ISIJ international, vol 32, issue 12, pp 1329-1338.

9. Houin J.P., Simon, A and Beck, G. 1981. "Relationship between Structure and Mechanical Properties of Pearlite between $0.2 \%$ and $0.8 \%$ C." Isij International 5 (3).

10. Królicka, A., Krzysztof R., Andrzej A. and Żak, A. 2019. Analysis of Grain Growth and Morphology of Bainite in Medium-Carbon Spring Steel. Materials Science and Engineering A, vol 768

11. Lee, Seok Jae, and Young Kook Lee. 2008. "Prediction of Austenite Grain Growth during Austenitization of Low Alloy Steels.” Materials and Design 29 (9): 1840-44.

12. Mendes Da Fonseca Gomes, Maria Das Graças, Luiz Henrique De Almeida, Luiz Claudio F.C. Gomes, and Iain Le May. 1997. "Effects of Microstructural Parameters on the Mechanical Properties of Eutectoid Rail Steels." Materials Characterization 39 (1): 1-14.

13. Porter, D. A., Easterling, K. E., \& Sherif, M. Y. 1992. Phase Transformations in Metals and Alloys.

14. Sellars, C. M., and J. A. Whiteman. 1979. "Recrystallization and Grain Growth'in Hot Rolling." Metal Science 13 (3-4): 187-94.

15. Sha, Q and Sun, Z. 2009 Grain growth behaviour of coarse-grained austenite in a Nb-V-Ti microalloyed steel. Mater Sci Eng; Vol. 523 pp. 77-84.

16. Seikh, H.A., Soliman, M.S., Almajid, A., Alhajeri, K. and Alshalfan, W. 2014. "Austenite Grain Growth Kinetics in API X65 and X70 Line-Pipe Steels during Isothermal Heating." Advances in Materials Science and Engineering 2014.

17. Yokoyama, Hiroyasu, Shinji Mitao, and Mineyasu Takemasa. 2002. "Development of High Strength Pearlitic Steel Rail (SP Rail) with Excellent Wear and Damage Resistance." NKK Technical Review 86 (86): $1-7$.

18. Yue, C., Zhang, L., Liao,S and Gao, H. 2010. "Kinetic Analysis of the Austenite Grain Growth in GCr15 Steel." Journal of Materials Engineering and Performance 19 (1): 112-15.

19. Zhang, S. S., Li ,M. Q., Liu ,Y. G., Luo, J and Liu, T. Q. 2011. "The Growth Behavior of Austenite Grain in the Heating Process of $300 \mathrm{M}$ Steel.” Materials Science and Engineering A, issue 528, pp4967-72. 